\title{
Research Paper: A Comparative Study of Prehospital a||(@) Emergency Services Over the Urban and Road Areas in Hamedan Province
}

\author{
Mehdi Beiramijam ${ }^{1}$, Shahnaz Salawati Ghasemi ${ }^{2}$, Masoomeh Khaleghverdi ${ }^{3}$, Kazem Bizhani $^{4}$, Ali Afshari ${ }^{3 *}$ iD, Majedeh Nabavian ${ }^{3,5}$ \\ 1. Research Center in Emergency \& Disaster Health, University of Social Welfare and Rehabilitation Sciences, Tehran, Iran. \\ 2. Department of Midwifery Information Management, School of Nursing and Midwifery, Kurdestan University of Medical Sciences, Sanandaj, Iran \\ 3. Department of Internal Medicine, School of Nursing and Midwifery, Hamadan University of Medical Sciences, Hamadan, Iran. \\ 4. Department of Medical Emergencies, Faculty of Nursing and Midwifery, Hamadan University of Medical Sciences, Hamadan, Iran \\ 5. Department of Nursing, Babol Branch, Islamic Azad University, Babol, Iran.
}

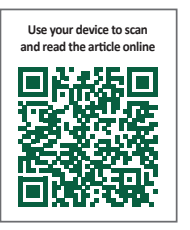

Cttation: Beiramijam M, Salawati Ghasemi Sh, Khaleghverdi M, Bizhani K, Afshari A, Nabavian M. A Comparative Study of Prehospital Emergency Services Over the Urban and Road Areas in Hamedan Province. Health in Emergencies and Disasters Quarterly. 2018; 4(1):23-28. http://dx.doi.org/10.32598/hdq.4.1.23

: http://dx.doi.org/10.32598/hdq.4.1.23

\section{(c) (i) (5)}

Funding: See Page 27

Article info:

Received: 10 Apr 2018

Accepted: 23 Aug 2018

Available Online: 01 Oct 2018

\section{Keywords:}

Prehospital emergency care services, Ambulance request, Urban emergency base, Rural emergency base

\section{ABSTRACT}

Background: Prehospital emergency care services are one of the vital health services in many countries that provide first and immediate medical care to the patients and injured people at the scene and during transfer to healthcare centers. This study was conducted to investigate and compare the use of prehospital emergency services in urban and road emergency bases of Hamadan University of Medical Sciences.

Materials and Methods: In a descriptive-analytic study, all missions (ambulance requests) conducted at urban and road emergency bases were studied and compared over three years. The study tool was a checklist compiled of questions from PCR (Patient Care Report). PCR contains written information about the patient's demographic characteristics, mission time, mission address, mission reasons, emergency base and mission code (ambulance identification code), and so on. Finally, the collected data were analyzed using descriptive (mean and variance) and inferential statistics ( $t$ test and Chi-square).

Results: The results of the study indicated that every year, urban bases missions increased about 600 and rural bases missions about 450 . Road traffic incidents, falls, cardiac emergencies and poisoning were the most common causes for ambulance call at urban and road emergency bases. In addition, urban and road bases missions were significantly different with regard to the cause of missions in all cases (except heat stroke) $(\mathrm{P}<0.01)$.

Conclusion: Understanding the number and pattern of prehospital emergency services in urban and rural areas plays a significant role in the proper planning of prehospital emergency care. The study showed that the need for emergency prehospital emergency services is increasing and policymakers should be considered this issue.

\section{* Corresponding Author: \\ Ali Afshari, PhD Student}

Address: Department of Internal Medicine, School of Nursing and Midwifery, Hamadan University of Medical Sciences, Hamadan, Iran.

E-mail: ali.ems77@gmail.com 


\section{Introduction}

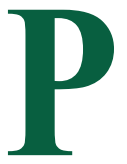

rehospital emergency medical services is one of the vital health services in many countries that provides first and immediate medical care for the patients and injured people in the scene of an accident and or during the transfer to health centers [1]. Medical Emergency System in Iran was established after the tragic accident of collapsing the roof of the waiting room at Mehrabad airport in Tehran (due to vibrations caused by the sound of jet aircraft engines) in 1975 as "115 Emergency" in cooperation with the United States (1975).

Like many other countries, by increasing people's need to services as well as due to population growth, urbanization, increased road accidents, more heart diseases, increased natural and industrial accidents, as well as increase in social disorders and other factors, the services and capabilities of this organization expanded gradually in Iran so that right now nearly 1900 prehospital emergency bases of 115 with nearly 3000 ambulances, 112 bus ambulance, air ambulance, and motorlance are operational throughout the country and more than two million missions have been accomplished by emergency stations only in 2010 [2-4].

Only three years after the first Emergency ambulance siren heard in the capital in 1979, Hamedan Emergency Center began its operation with the opening of the first base on Pasteur Street and expanded parallel with the expansion of the country's emergency centers. Having 41 bases in the province with 60 ambulances, one ambulance bus, one air ambulance (helicopter), and 315 emergency medical technicians, the center now render services all over the cities and roads of the province $[5,6]$.

Several studies have recently been conducted on the use of emergency medical services in different regions and countries [7-9] regarding the fact that the use of prehospital emergency services is different depending on patient's age, type and significance of the incident and illness, access to health services, and the economic, social, and cultural status. However, for the proper planning of prehospital emergency care in various (urban and rural) geographic regions in the country, it is necessary to understand the pattern and the use of emergency prehospital emergency services in these areas. Lyshnner et al. study reports that prehospital emergency services is used less by people living in rural areas compared to those living in urban areas $[1,9]$.
In the study by Billon et al. the most common ambulance calls in urban and rural areas have been reported for heart diseases, trauma, low consciousness and respiratory problems [10]. In the literature, there are few, if any, studies on patterns, number, and reason for prehospital emergency services in the urban and rural bases of Iran. Therefore, we decided to conduct a study to investigate and compare the usage pattern of prehospital emergency services in urban and road bases of Hamedan Medical Emergency Center.

\section{Materials and Methods}

In this descriptive-analytic study which was conducted with a cross-sectional design, the results of all "ambulance calls" made by the clients and people living in the urban and medical bases of the University of Medical Sciences and Hamedan Health Services were reviewed from 2012 to 2014. The study instrument in this study was a researcher-made checklist derived from items in "Patient Care Report" (PCR), which is used in the prehospital emergency system of the country to record mission reports.

This form contains information about patient's demographic characteristics, ambulance dispatch address, ambulance dispatch time, the reason for the dispatch of the ambulance, name of the base and ambulance departures, patient's medical history and medications, associated symptoms, and also the result of the mission. This form is completed by ambulance personnel during the mission and will be archived at the Emergency Medical Center of each city. It should be noted that the main information of these forms is recorded as a portal in the information registration system and 115 missions at the University Hospital Accident and Emergency Management Center. Checklist used in this study contains questions for research purposes, including response time (from receiving an ambulance call until the ambulance arrives at the desired location), the address and location of the mission, reason for calling the ambulance, the base and the code (the ambulance identification code) of the missioner and the result of the mission.

To observe ethical considerations in collecting data, the research project was approved by the Student Research Committee of the University of Medical Sciences and Hamedan Health Services. Then a letter of introduction from that center was provided to Hamedan Medical Center of Accidents and Emergencies and after obtaining the necessary permissions, the study information was collected. Finally, the collected data were analyzed using descriptive statistical methods 
(such as mean and variances) and appropriate statistical tests (such as t test and Chi-square test).

\section{Results}

Based on the study results, out of 40 prehospital emergency bases available in the province, 18 are urban bases and 22 road bases. Moreover, from 2012 to 2014, respectively 19393, 19945, and 20545 cases of ambulance calls have been recorded every year in the urban bases and 5165,5704 , and 6151 calls recorded from the road bases. Approximately 600 and 450 cases of ambulance calls increased annually in urban and road bases, respectively. The results also indicate that the most common causes of ambulance calls at urban and road bases were traffic accidents, falling, heart diseases, and poisoning.

Comparing the cause of the ambulance call between urban bases and road bases, statistical analysis indicated a significant difference with respect to causes such as traffic accidents, heart emergencies, respiratory emergencies, brain emergencies, falling, burns, suicide, poisoning, and drowning $(\mathrm{P}<0.01)$, while this difference was not significant with regard to heat stroke $(\mathrm{P}<0.01)$ (Table 1). The average call response time at the urban base was 5.87 minutes and on the road bases, 10.59 minutes. Statistical test showed a significant difference between response time at urban and road bases $(\mathrm{P}<0.01)$ (Table 2). In most cases of the ambulance call at urban bases (63.14\%) and road bases (73.01\%), the injured people were transferred to the health centers (Table 3 ).

\section{Discussion}

Findings of the study indicate an increase in ambulance calls from road and urban emergency bases each year. The highest number of causes for ambulance calls from urban and road bases for all three years were related to traffic accidents and the least number was related to heat stroke. In Kavusi et al. study, the most common cause of ambulance use was related to receiving consulting services $(20.5 \%)$, laboratory services, and transfusion of blood products $(12.5 \%)$ [11]. In a study by Stripe et al. which was conducted with the aim of comparing the profile of Nebraska prehospital missions, transfer of the patients with fractures, cardio-respiratory and neurological diseases were reported more in rural areas and also the possibility of admission of patients from rural areas was twice as many as from urban areas [12].

In this study, traffic incidents, falling, heart emergency and poisoning were the most common causes for ambulance calls from urban and road bases and there was a significant difference between urban and rural areas with regard to all causes (except for heat stroke) $(\mathrm{P}<0.01)$. In a study by Billion et al. problems such as chest pain (symptom of heart problem), clinical signs associated with abdominal and urinary problems, traffic accidents, respiratory problems, and organ

Table 1. Comparison of the causes of ambulance call on the road and urban bases of the province from 2012 to 2014

\begin{tabular}{|c|c|c|c|c|c|c|c|}
\hline \multirow{2}{*}{ Cause of Call } & \multicolumn{3}{|c|}{ Urban Base } & \multicolumn{3}{|c|}{ Road Base } & \multirow{2}{*}{$\begin{array}{l}\text { P With Chi- } \\
\text { Square Test }\end{array}$} \\
\hline & No. & $\begin{array}{c}\text { Cases Per } \\
1000 \text { People }\end{array}$ & $\%$ & No. & $\begin{array}{c}\text { Cases Per } \\
1000 \text { People }\end{array}$ & $\%$ & \\
\hline Traffic accidents & 12569 & 12.08 & 20.98 & 11232 & 15.68 & 66.40 & $<0.01$ \\
\hline Cardiac emergencies & 5374 & 5.16 & 8.97 & 727 & 1.01 & 4.30 & $<0.01$ \\
\hline Head emergencies & 625 & 0.60 & 1.04 & 81 & 0.11 & 0.47 & $<0.01$ \\
\hline Respiratory emergencies & 2301 & 2.212 & 3.84 & 310 & 0.43 & 1.83 & $<0.01$ \\
\hline Falling & 3429 & 3.297 & 5.726 & 624 & 0.87 & 3.69 & $<0.01$ \\
\hline Burns & 289 & 0.277 & 0.48 & 107 & 0.15 & 0.633 & $<0.01$ \\
\hline Suicide & 337 & 0.324 & 0.56 & 46 & 0.06 & 0.27 & $<0.01$ \\
\hline Poisoning & 3564 & 3.42 & 5.951 & 427 & 0.59 & 2.52 & $<0.01$ \\
\hline Drowning & 17 & 0.016 & 0.028 & 15 & 0.12 & 0.08 & $<0.01$ \\
\hline Heat stroke & 3 & 0.002 & 0.005 & 2 & 0.002 & 0.01 & $>0.01$ \\
\hline Others & 31375 & 30.16 & 52.39 & 3439 & 4.80 & 20.34 & $<0.01$ \\
\hline
\end{tabular}


Table 2. Average response time

\begin{tabular}{ccc}
\hline Base & Average Response Time (Min) & P With t \\
\hline Urban & 5.87 & $<0.01$ \\
Road & 10.59 & \multicolumn{1}{|l|l|l|l|l|}{ in } \\
\hline
\end{tabular}

Table 3. The result of an ambulance call

\begin{tabular}{ccccc}
\hline \multirow{2}{*}{ Result } & \multicolumn{2}{c}{ Urban Base } & \multicolumn{2}{c}{ Road Base } \\
\cline { 2 - 5 } & No. & $\%$ & No. & $\%$ \\
\hline Transferring to health center & 40365 & 63.14 & 15659 & 73.01 \\
On-site treatment & 2941 & 4.60 & 1466 & 6.83 \\
Cancelled mission & 18441 & 28.84 & 3636 & 16.95 \\
Death at the mission location & 2180 & 3.41 & 684 & 3.18 \\
\hline
\end{tabular}

damage were reported among the reasons for the ambulance calls in urban and rural areas [10]. However, in Huang et al. study, aimed at examining the pattern of use of prehospital emergency services in urban and rural areas, a statistically significant difference was found among reasons such as traffic accidents, falling, acute illness, alcohol poisoning in urban and rural areas $(\mathrm{P}<0.01)$.

Traffic accidents were the most common cause of ambulance calls in rural areas and acute illness and traffic accidents were the common causes of calling in urban areas [13]. According to the obtained results, the highest result regarding the dispatching of ambulances in urban bases in all three years was ambulance dispatch to health centers and its lowest number was related to the cancellation of the mission due to the death of the patient at the call place of the ambulance.

"Response duration" has been used as an indicator of the evaluation of the prehospital emergency system process freely all over the world and that was one of the traditional ways in assessing the performance of prehospital emergency bases $[14,15]$. Based on the results, the average response time at dispatching ambulance in urban areas was 5.87 minutes and in the road bases was 10.59 minutes. This means that this duration on the road was almost twice the duration of urban bases and based on the statistical test in relation to the response time, a significant statistical difference was observed between the urban and road bases in this regard $(\mathrm{P}<0.01)$.

The longer response time on the road bases can be because of the wider coverage area of the road bases of Hamadan Province, compared to the urban bases. That is because the distance between the mission area and the road base may be further. In a study by Peyravi et al. which conducted with the aim of investigating the response time to emergency cases and causes of delays in the missions of the Emergency Center, Shiraz, the results indicate that in all hours of the day and night, $49.9 \%$ of missions were accomplished between 8 and 10 minutes, that is, more than the standard time. The causes of this delay mentioned by the technicians were road failures, road traffic, bad weather, long route, dispatch from other bases due to lack of ambulance at the base of the relevant area, getting the wrong address by operator, failure to send an ambulance, delay in sending ambulance at the beginning of the mission [16].

In line with the results of this study, Nasiri Pour et al. in their study reported that an emergency response time in urban areas of the whole country except Tehran was 7 minutes and in suburban areas was 14 minutes [17]. Jack Campbell in his study reported that emergency road response was more than 10 minutes, and thus, more than global standards [18]. According to Fitch, the standard response time in urban areas was within 8 minutes and 59 seconds to $90 \%$ of calls and in rural areas, 14 minutes and 59 seconds response time to $90 \%$ of calls [19].

Based on the results, there have been approximately 600 more calls for ambulances every year from urban bases and 450 calls for ambulances from the road bases. The number of ambulance calls from urban bases was more than that of the road bases. This indicates that the need for prehospital emergency services is rising in urban and rural areas each year. Along with these results, 
in the study by Huang et al., the size and number of missions that led to therapeutic measures in urban areas was more than that in rural areas [13].

In another study by Momeni et al. aimed at comparing the use of ambulances in patients with acute myocardial infarction in urban and rural areas, the findings revealed that $9.9 \%$ of urban patients and $7.4 \%$ of rural patients had used ambulance; but this difference was not statistically significant $(\mathrm{P}>0.58)$ [20]. The main limitations of this study is the nongeneralizability of the results due to the small size of the research population as it only researched the roads and urban bases located in Hamedan Province. Therefore, it is recommended that other studies be conducted in other provinces of the country to draw a better conclusion.

\section{Conclusion}

According to the results of the study, despite the similarity in the order of the reasons for the ambulance calls from the road and urban bases, significant differences observed between urban and road areas regarding the number of "ambulance calls" and "response time". Although ambulance calls in urban areas was more than that of the rural areas, but the response time in rural areas was longer than urban areas and this difference can be due to the greater awareness of prehospital emergency services in residents of urban areas and the vast and large area covered by the road emergency base, compared to that of urban emergency bases. Therefore, it is necessary to increase the number of road emergency bases (rural areas) to reduce the response time.

It was also shown that the number of ambulance calls and 115 missions in urban and rural areas increased annually. Therefore, the authorities should perform precise need measurement in their planning to increase the number of road and urban emergency bases according to the needs. Since in this study, traffic accidents, falling, heart emergency and poisoning were the most common causes for ambulance calls from urban and road bases, the authorities in prehospital emergency department of the province are expected to promote road and urban ambulances equipment and prepare appropriate in-service training programs in order to improve care services in connection with these causes.

\section{Ethical Considerations}

\section{Compliance with ethical guidelines}

There is no ethical principle to be considered doing this research.

\section{Funding}

This article is derived from a student research project approved by the University of Medical Sciences and Hamedan Health Services (Reg. No. 940201311).

\section{Authors contributions}

All the authors have read and approved the manuscript.

\section{Conflict of interest}

The authors declare no conflict of interest.

\section{Acknowledgments}

Authors hereby express their thanks and gratitude towards the Deputy Research Director and respected members of the Faculty of Nursing of Hamedan University of Medical Sciences, employees of the Center for Accidents Management and Emergencies of Hamedan Province, and all those who assisted them in conducting this study.

\section{References}

[1] Eagle DJ, Rideout E, Price P, McCann C, Wonnacott E. Misuse of the emergency department by the elderly population: Myth or reality? Journal of Emergency Nursing. 1993; 19(3):212-8. [PMID]

[2] Bahadori M, Nasiripur A, Tofighi S, Gohari M. Emergency medical services in Iran: An Overview. Australasian Medical Journal. 2010; 3(6):335-9. [DOI:10.4066/AMJ.2010.218]

[3] Bahadori M, Ravangard R, Nejati M. Development of Emergency Medical Services (EMS) in Iran: Component of transportation. Journal of Society for Development in New Net Environment in B\&H. 2012; 3(6):826-31.

[4] Khankeh H. Hospital preparedness in disaster \& emergencies (National Plan). Tehran: University of Social Welfare and Rehabilitation Sciences; 2013.

[5] Emergency Medicine Management of Hamadan University of Medical Sciences. [The history of Hamadan province Emergency services (Persian)] [Internet]. 2017 [Updated 2017 August 4]. Available from: http://ems.umsha.ac.ir/index. aspx?siteid $=42 \&$ pageid $=2927$

[6] Emergency Medicine Management of Hamadan University of Medical Sciences. [Air ambulance (Persian)] [Internet]. 2017 [Update 2017 August 4]. Available from: http://mbohumshaacir $/$ indexaspx?fkeyid=\&siteid=14\&pageid=7975\&n ewsview $=18785$

[7] Lishner DM, Rosenblatt RA, Baldwin LM, Hart LG. Emergency department use by the rural elderly 22 . Journal of Emergency Medicine. 2000; 18(3):289-97. [DOI:10.1016/ S0736-4679(99)00217-6 
[8] Mann NC, Schmidt TA, Cone DC. Defining research criteria to characterize medical necessity in emergency medical services: A consensus among experts at the Neely conference. Prehospital Emergency Care. 2004; 8(2):138-53. [DOI:10.1016/j.prehos.2003.12.005] [PMID]

[9] Snooks H, Wrigley H, George S, Thomas E, Smith H, Glasper A. Appropriateness of use of emergency ambulances. Journal of Accident \& Emergency Medicine. 1998; 15(4):2128. [DOI:10.1136/emj.15.4.212]

[10] Beillon LM, Susrud B, Kalberg I, Heriltz J. Dose ambulance use difference between geographic aria? A survey of ambulance use in sparsely and densely populated areas. American Journal of Emergency Medicine. 2009; 27(2):202-11. [DOI:10.1016/j.ajem.2008.01.012] [PMID]

[11] Kavosi Z, Ahmadzadeh M, Moradi R. [Study of the ambulance use in hospital of Shiraz University of Medical Sciences (Persian)]. Journal of Healthcare Management. 2015; 6(4):19-28.

[12] Stripe SC, Susman J. A rural-urban comparison of prehospital emergency medical services in Nebraska. The Journal of the American Board of Family Practice. 1991; 4(5):313-18. [PMID]

[13] Huang CH, Chen WJ, Ma MHM, Lai CL, Lin FY, Lee YT. Ambulance utilization in metropolitan and rural areas in Taiwan. Journal of The Formosan Medical Association. 2001; 100(9):581-6. [PMID]

[14] Al-Shaqsi SZK. Response time as a sole performance indicator in EMS: Pitfalls and solutions. Open Access Emergency Medicine. 2010; 2(3):1-6. [DOI:10.2147/OAEM.S8510] [PMID]

[15] Murphy A, Wakai A, Walsh C, Cummins F, O'sullivan R. Development of key performance indicators for prehospital emergency care. Emergency Medicine Journal. 2016; 7(2):1527. [DOI:10.1136/emermed-2015-204793]

[16] Peyravi M R, Moradian M J, Ettehadi R, Pourmohammadi K. [Studying the time of response and results of delay in emergency medical systems (Persain)]. Quarterly Scientific Journal of Rescue and Relief. 2013; 5(2):30-9.

[17] Nasiripur AA, Bahadori MK, Tofighi SH, Gohari MR. Prehospital emergency performance in Iran view of comprehensive coverage plan. Journal of Critical Care Nursing. 2010; 2(4):3-4.

[18] Campbell JP, Kroshus KS, Lindholm DJ, Watson WA. Measuring the call-receipt-to-defibrillation interval: Evaluation of prehospital methods. Annals of Emergency Medicine. 1995; 26(6):697-701. [DOI:10.1016/S0196-0644(95)70040-4]

[19] Fitch J. Response times: Myths, measurement \& management. Journal of Emergency Medical Services. 2005; 30(9):4756. [DOI:10.1016/S0197-2510(05)70201-1]

[20] Momeni M, Zand Parsa A, Salari A, Ghanbari Khanghah A, Moghadas T. [Comparison of ambulance use in urban and rural patients with acute myocardial infarction (Persian)]. Journal of Holistic Nursing and Midwifery. 2014; 24(2):59-67. 